\title{
Voltage-Dependent Enhancement of Electrical Coupling by a Subthreshold Sodium Current
}

\author{
Sebastián Curti and Alberto E. Pereda \\ Department of Neuroscience, Albert Einstein College of Medicine, Yeshiva University, Bronx, New York 10461
}

\begin{abstract}
Voltage-dependent changes in electrical coupling are often attributed to a direct effect on the properties of gap junction channels. Identifiable auditory afferents terminate as mixed (electrical and chemical) synapses on the distal portion of the lateral dendrite of the goldfish Mauthner cells, a pair of large reticulospinal neurons involved in the organization of sensory-evoked escape responses. At these afferents, the amplitude of the coupling potential produced by the retrograde spread of signals from the postsynaptic Mauthner cell is dramatically enhanced by depolarization of the presynaptic terminal. We demonstrate here that this voltage-dependent enhancement of electrical coupling does not represent a property of the junctions themselves but the activation of a subthreshold sodium current present at presynaptic terminals that acts to amplify the synaptic response. We also provide evidence that this amplification operates under physiological conditions, enhancing synaptic communication from the Mauthner cells to the auditory afferents where electrical and geometrical properties of the coupled cells are unfavorable for retrograde transmission. Retrograde electrical communication at these afferents may play an important functional role by promoting cooperativity between afferents and enhancing transmitter release. Thus, the efficacy of an electrical synapse can be dynamically modulated in a voltage-dependent manner by properties of the nonjunctional membrane. Finally, asymmetric amplification of electrical coupling by intrinsic membrane properties, as at the synapses between auditory afferents and the Mauthner cell, may ensure efficient communication between neuronal processes of dissimilar size and shape, promoting neuronal synchronization.
\end{abstract}

Key words: gap junctions; persistent sodium current; Mauthner; electrical synapse; synchronization; auditory; synaptic plasticity

\section{Introduction}

One of the most prominent properties of gap junction-mediated electrical synapses is their characteristic bi-directionality that promotes coordinated neural activity (Bennett, 1977). The strength of electrical transmission depends not only on the conductance of the gap junction channels but also on the electrical and geometrical characteristics of the coupled cells (Bennett, 1966, 1977), which are determined to a large extent by their morphology and membrane properties. Thus, in addition to the control of gap junctional conductance itself (Furshpan and Potter, 1959; Auerbach and Bennett, 1969; Piccolino et al., 1982; Lasater and Dowling, 1985; Yang et al., 1990; Pereda et al., 1992, 1998), changes in the conductance of the nonjunctional membrane are known to have a profound impact on electrical coupling (Kandel and Tauc, 1966; Spira et al., 1976; Zipser, 1979). In the mammalian CNS, neuronal gap junctions are often localized between small dendritic processes of dissimilar size and shape (Llinás et al., 1974; De Zeeuw et al., 1995; Fukuda and Kosaka, 2000; Fukuda and Kosaka, 2003) where geometry may favor transmis-

Received Nov. 13, 2003; revised March 9, 2004; accepted March 9, 2004.

This work was supported by National Institutes of Health Grant DC03186 to A.P. S.C. was partially supported by Consejo Superior de Investigaciones Científicas (Uruguay) and International Brain Reserch Organization fellowships. We thank K. Khodakhah, R. Cachope, P. Castillo, V. Verselis, and M. V. L. Bennett for critically reading this manuscript.

Correspondence should be addressed to Alberto E. Pereda, Department of Neuroscience, Albert Einstein College of Medicine, 1300 Morris Park Avenue, Bronx, NY 10461. E-mail: apereda@aecom.yu.edu.

DOI:10.1523/JNEUROSCI.0077-04.2004

Copyright $\odot 2004$ Society for Neuroscience $\quad$ 0270-6474/04/243999-12\$15.00/0 sion in one direction or the other. Recent evidence showed that amplification of electrical coupling by intrinsic membrane properties (Mann-Metzer and Yarom, 1999; Schmitz et al., 2001) plays an essential role in promoting the synchronization of weakly coupled neuronal networks (Traub, 1995; Mann-Metzer and Yarom, 1999), suggesting a role for voltage-dependent membrane properties in regulating transmission at electrical synapses.

Auditory afferents terminating as mixed (electrical and chemical) synapses known as large myelinated club endings on the goldfish Mauthner (M-) cells ("club endings") (Bartelmez, 1915; Furshpan, 1964; Nakajima, 1974; Lin and Faber, 1988) provide a convenient in vivo model in the vertebrate CNS, amenable to experimental manipulation, to study how efficient bi-directional communication is achieved despite unfavorable electrical and geometrical conditions. This relatively homogeneous group of synaptic contacts is tightly segregated to the distal portion of the lateral dendrite of the M-cells (Bartelmez, 1915), a pair of large reticulospinal neurons responsible for the organization of escape responses evoked by sound and other senses (Eaton et al., 2001). Despite the fact that the geometry and electrical properties of M-cells favor the spread of postsynaptic depolarizations from this remote dendritic site toward the lower-impedance soma of the cell (Faber and Korn, 1986), the postsynaptic depolarization produced by the activation of some of these afferents can be recorded as a coupling potential in neighboring, inactive terminals (Pereda et al., 1995). Thus, these electrical synapses are bi-directional, and terminals are interconnected through the M-cell lateral dendrite, 
thereby forming a functional compartment. The retrograde spread of dendritic depolarizations to the presynaptic club endings influences their excitability (Pereda et al., 1995), promoting the cooperativity between afferents. This mechanism is believed to promote the synchronization of these auditory afferents and enhance the synaptic potential evoked by them (Pereda et al., 1995; Smith and Pereda, 2003).

Previous data showed that electrical transmission from the M-cells to the club endings is voltage dependent (Pereda et al., 1995); that is, the amplitude of the coupling potential produced by the retrograde spread of postsynaptically originated signals is dramatically enhanced by depolarization of the presynaptic terminal. This phenomenon might play an essential physiological role, because it would act to enhance communication between afferents. The mechanism underlying this voltage dependence remains unknown. Voltage-dependent changes of electrical coupling are generally attributed to voltage-dependent properties of the gap junction channels (Furshpan and Potter, 1959; Auerbach and Bennett, 1969; Giaume and Korn, 1983; Edwards et al., 1991). Here we show that the observed enhancement does not represent a property of the gap junctions themselves but rather a property of the nonsynaptic membrane of the presynaptic afferent. More specifically, electrophysiological and pharmacological evidence show that the observed voltage-dependent enhancement results from the activation of a subthreshold sodium $\left(\mathrm{Na}^{+}\right)$ conductance present at these terminals. Furthermore, we provide evidence that this amplification operates under physiological conditions, suggesting that it plays a relevant role in the processing of sensory information of this auditory input.

\section{Materials and Methods}

For these experiments, goldfish (Carassius auratus) were used, and the surgical and in vivo recording techniques were similar to those described previously (Lin and Faber, 1988; Pereda et al., 1995). Individual VIIIth nerve afferents $(n=161)$ were penetrated either outside the brain or, less often, intracranially close to the dendrite. Recording electrodes were filled with $2.5 \mathrm{M} \mathrm{KCl}(30-45 \mathrm{M} \Omega)$. Afferents with electrical synapses on the M-cell were identified by the presence of electrotonic coupling potentials when the M-cell antidromic spike was evoked by stimulating the spinal cord (see Fig. 1A). For simultaneous recordings with the lateral dendrite of the M-cell, a second electrode ( $5 \mathrm{M} \mathrm{KAc} ; 4-12 \mathrm{M} \Omega$ ) was either placed in the axon cap of this cell for extracellular recordings or inserted 350-400 $\mu \mathrm{m}$ lateral from it in the lateral dendrite during intracellular recordings. A bipolar stimulating electrode placed on the posterior VIIIth nerve distal to the recording site was used to activate VIIIth nerve fibers. For acoustic stimulation, sound stimuli consisted of a $500 \mu \mathrm{sec}$ broadband noise burst delivered by a 2.5 inch speaker (Quam; frequency response, $0.2-8 \mathrm{kHz}$ ) located 4 inches from the animal's head and connected to a Grass AM8 Audiomonitor. Resting and action potentials of afferents averaged $-71.3 \pm 0.36 \mathrm{mV}(\mathrm{SEM} ; n=161)$ and $88 \pm 1.1 \mathrm{mV}$ (SEM; $n=150$ ), respectively. The input resistance of the afferents averaged 8.5 M $\Omega( \pm 0.63 \mathrm{SEM} ; n=29)$. Because of the fast time constant of the afferent fibers (comparable with that of the M-cell, estimated in $\sim 400$ $\mu \mathrm{sec}$ ) (Fukami et al., 1964), the bridge was balanced using the spikeheight method (Frank and Fuortes, 1956). The M-cell resting and action potentials averaged $-76.3 \pm 1.3$ and $21.2 \pm 1.1 \mathrm{mV}($ SEM; $n=23)$, respectively. The fish's brain was superfused continuously $(1.5 \mathrm{ml} / \mathrm{min})$ with artificial CSF containing (in $\mathrm{mM}$ ): $124 \mathrm{NaCl}, 5.1 \mathrm{KCl}, 3.0 \mathrm{NaH}_{2} \mathrm{PO}_{4}$ $\mathrm{H}_{2} \mathrm{O}, 0.9 \mathrm{MgSO}_{4}$, 5.6 dextrose, $1.6 \mathrm{CaCl}_{2}-\mathrm{H}_{2} \mathrm{O}$, and 20 HEPES, $\mathrm{pH} 7.2-$ 7.4. Experimental drugs were either added to the intracellular recording solution [ $50 \mathrm{~mm}$ lidocaine $N$-ethyl bromide (QX-314), 0.5-1.0 M TEA$\mathrm{Cl}, 0.075-0.15 \mathrm{M} 4$-aminopyridine, $1 / 2 \mathrm{M} \mathrm{CsCl}]$ or topically applied to the surface of the posterior VIIIth nerve [1-10 $\mu \mathrm{M}$ tetrodotoxin (TTX)]. Experimental data were acquired and recorded on a Macintosh G4 computer equipped with a National Instruments A-D card (Austin, TX) and software developed in the laboratory (sampling intervals, 5-30 $\mu \mathrm{sec}$ ).
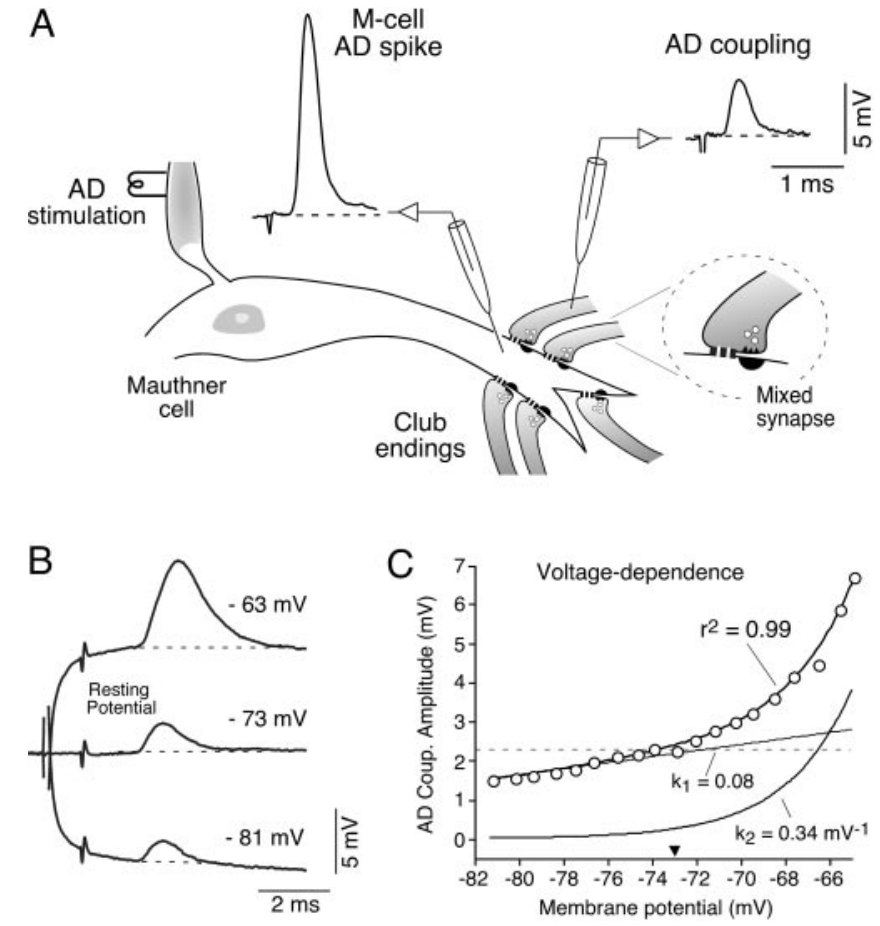

Figure 1. The antidromic coupling is a convenient tool to study retrograde transmission at club endings. $A$, Experimental arrangement. Auditory afferents (Club endings) terminate as mixed synapses (Mixed synapse) on the lateral dendrite of the Mauthner (M-) cell. The action potential produced by the antidromic stimulation of the M-cell axon in the spinal cord (M-cell $A D$ spike) can be recorded as a coupling potential in the presynaptic afferents ( $A D$ coupling). The presynaptic recordings were either intracranial (this case) or more often in the VIIIth nerve root. $B$, The AD coupling is voltage dependent, increases with presynaptic membrane depolarization, and decreases with membrane hyperpolarization (current pulses of $\pm 0.9 \mathrm{nA}$; recording site in the VIIIth nerve root). Here and elsewhere, unless indicated, traces represent the average of at least 10 single responses. C, Quantitative analysis of the voltage dependence of AD coupling suggests the existence of two mechanisms. Relationship between the antidromic coupling potential (AD coup.; Amplitude, ordinates) and the presynaptic membrane potential (Membrane potential, abscissa) is shown. The data (open circles) were fit with a function representing the sum of an exponential and a straight line $\left[A D\right.$ coup $\left.=\left(A+k_{1}{ }^{*} V_{m}\right)+B^{*} e^{k 2^{*} V m}\right]$ and the two calculated components are also plotted alone $\left(k_{1}, k_{2}\right)$. The resting potential (arrowhead) in this case was $-73 \mathrm{mV}$. The horizontal dotted line represents the expected behavior if the coupling potential was not voltage dependent.

Data analysis was performed using Kaleida Graph (Synergy Software) and Igor Pro (Wave Metrics) software. Student's $t$ test was used to assess statistical significance of the data.

\section{Results}

Retrograde electrical transmission from the M-cell dendrite to presynaptic club endings is enhanced by depolarization of the afferent (Pereda et al., 1995). To investigate the mechanism underlying this phenomenon, we examined the voltage dependence of the antidromic coupling potential (AD coupling), the electrotonic coupling potential intracellularly recorded in the afferents caused by the passive dendritic depolarization produced by the antidromically evoked $\mathrm{M}$-cell action potential (Fig. $1 A$ ). The AD coupling is a distinctive feature of the club endings (Furshpan, 1964) and a convenient way to study retrograde transmission; it was used instead of that produced by activating other VIIIth nerve afferents to avoid possible complications attributable to local responses produced by changes in axonal excitability after the nerve stimulation. The voltage dependence of $\mathrm{AD}$ coupling potential was investigated by pairing this potential with presynaptic depolarizing and hyperpolarizing currents $( \pm 0.9 \mathrm{nA})$ (Fig. 

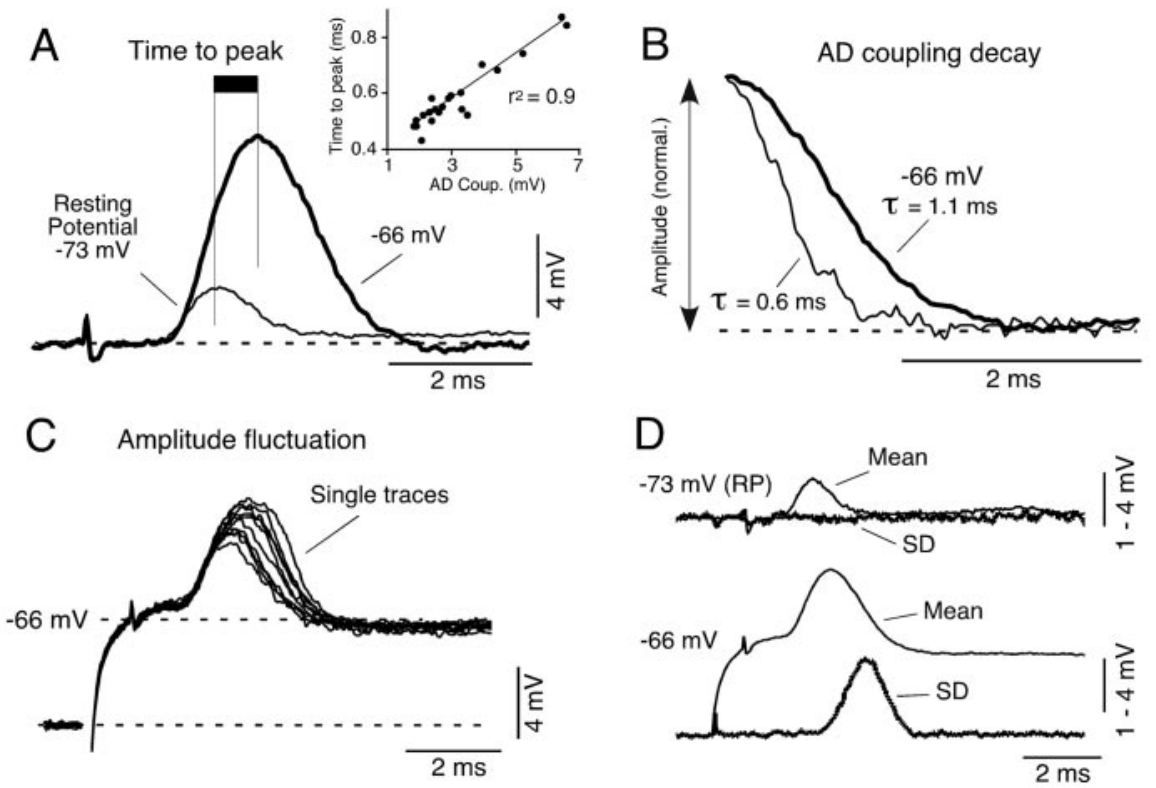

Figure 2. Kinetics of the voltage-dependent enhancement of electrical coupling. $A$, Depolarization not only increases the amplitude of the response but also its time-to-peak. Superimposed traces show the antidromic coupling potential recorded at resting potential $(-73 \mathrm{mV})$ and at near the threshold of the cell $(-66 \mathrm{mV})$. Note the increased time-to-peak of the depolarization-enhanced response. Inset, Relationship between the amplitude of the AD coupling (abscissa) and its time-to-peak (ordinate) obtained at different membrane potentials for the same fiber. Depolarization increased proportionally both the amplitude and the time-to-peak of $A D$ coupling. $B$, Depolarization also slows the time course of the decay of the coupling potential. Superimposed traces represent the normalized decays of the recordings illustrated in $A$. There is almost a twofold increase in the estimated time constant of the decay at depolarized potentials ( $0.6 \mathrm{vs} 1.1 \mathrm{msec}$ ). C, Depolarization-enhanced responses fluctuate in amplitude. Superimposed traces represent single consecutive responses obtained at $-66 \mathrm{mV}$; note the variability in the amplitudes of the $A D$ couplings. $D$, Statistical analysis of amplitude fluctuation of the $A D$ coupling at depolarized membrane potentials. Superimposed traces illustrate the averaged (mean; calibration, $4 \mathrm{mV}$ ) responses with its SDs (SD; calibration, $1 \mathrm{mV}$ ) obtained at resting potential (top) and $-66 \mathrm{mV}$ (bottom) in the same experiment. Note the increase of the SD in the falling phase of the depolarization-enhanced response.

$1 B$ ). As described previously (Pereda et al., 1995), the amplitude of the $\mathrm{AD}$ coupling is dramatically enhanced by membrane depolarization and reduced, although to a lesser extent, by hyperpolarization (Fig. $1 \mathrm{~B}$ ). The amplitude of the responses at depolarized potentials averaged $262 \%$ of its value at the resting potential ( \pm 14.7 SEM; to allow comparison, here and elsewhere, unless indicated otherwise, the values of the depolarized responses were measured just below the firing threshold of the afferent by the coupling potential, which is approximately -65 $\mathrm{mV})$. In contrast, that obtained during hyperpolarization averaged only 58\% ( \pm 7.4 SEM; same current used to depolarize the afferent but of negative value) of its amplitude at resting potential. Examined in more detail in Figure $1 C$, the slope of the relationship of the AD coupling amplitude with the membrane potential of the afferent increases sharply with depolarization (the horizontal dotted line in the same figure represents the expected behavior if the coupling potential was not voltage dependent). Such supralinear voltage-dependent behavior observed between resting membrane potential and the threshold of the cell is characteristic of amplifying subthreshold currents (Crill, 1996). The linear decrease in amplitude with membrane hyperpolarization, on the other hand, cannot be attributed to this process, suggesting the existence of two coexisting voltage-dependent mechanisms.

We first attempted to isolate those putative mechanisms mathematically. In contrast with a previous report in which data from a single fiber were fit with a double exponential (Pereda et al., 1995), we analyzed the quantitative relationship of the AD coupling with the membrane potential in a larger number of afferents $(n=20)$ using instead a function representing the sum of an exponential and a straight line according to the following expression: $\mathrm{AD}$ coup $=\left(A+k_{1}{ }^{\star} V_{\mathrm{m}}\right)$ $+B^{\star} e^{\mathrm{k} 2^{\star} \mathrm{Vm}}$, where $\mathrm{AD}$ coup is the AD coupling potential amplitude and $V_{\mathrm{m}}$ is the value of the membrane potential. The form of this relationship was established empirically, and it was superior to a single exponential $\left(r_{2}\right.$ values averaged 0.94 for the single exponential and 0.98 for the applied fit; $p<0.0001)$. The constant values obtained for this afferent were 0.08 and $0.34 \mathrm{mV}^{-1}$ ( $k_{1}$ and $k_{2}$, respectively), and they are plotted as functions of the membrane potential in the same figure. The values obtained for this example represent those of the population because the $k_{1}$ and $k_{2}$ values estimated for 20 afferents averaged $0.083( \pm 0.009 \mathrm{SEM})$ and $0.42 \mathrm{mV}^{-1}$ ( \pm 0.072 SEM), respectively.

The quantitative analysis of the voltage dependence of $\mathrm{AD}$ coupling suggests the existence of two different mechanisms. The steep voltage constant $\left(k_{2}\right)$ suggests the existence of a mechanism that is only activated by depolarization. This mechanisms is responsible to a large extent for the amplification of AD coupling potential at depolarized membrane potentials, representing $\sim 80 \%$ of the total enhancement observed at $-65 \mathrm{mV}$ (Fig. 1C). An additional mechanism, represented by a lower and symmetric linear dependence to voltage in the vicinity of the resting potential $\left(k_{1}\right)$, accounts for only $\sim 20 \%$ of the enhancement observed at depolarized potentials (Fig. 1C). Because of its overall contribution and supralinear character, the $k_{2}$ component is primarily responsible for the voltage-dependent amplification of $\mathrm{AD}$ coupling, and it could represent, given its voltage sensitivity and membrane-potential range, the activation of a voltage-sensitive conductance in the presynaptic terminal.

\section{Kinetics and time dependence of depolarization-enhanced responses suggests the activation of a subthreshold conductance}

Although the waveform of the depolarization-enhanced AD coupling is remarkably similar to that observed at resting and hyperpolarized potentials, detailed analysis of its kinetics revealed differences that are consistent with the progressive activation of a subthreshold voltage-dependent membrane conductance. Three lines of evidence support this conclusion. (1) The time-to-peak of the $\mathrm{AD}$ coupling potential, measured about the threshold of the afferent, was increased when compared with that obtained at resting potential (Fig. $2 A$ ), averaging $1.13 \mathrm{msec}( \pm 0.06 \mathrm{SEM} ; n=$ $35)$ and $0.72 \mathrm{msec}( \pm 0.03 \mathrm{SEM} ; n=38)$, respectively $(p<$ 0.0001). Furthermore, both the amplitude of the AD coupling and its time-to-peak were proportionally affected by increasing membrane depolarization (Fig. $2 A$, inset). (2) The time constant of the decay of the depolarization-enhanced response was found to be increased by almost twofold (Fig. $2 B$ ). The estimated time constants of the decays averaged $1.38 \mathrm{msec}( \pm 0.16 \mathrm{SEM})$ and 0.73 $( \pm 0.05 \mathrm{SEM})$, for the responses obtained at depolarized and rest- 
ing potentials, respectively $(n=35 ; p<$ 0.0002). (3) The depolarization-enhanced AD coupling fluctuated in amplitude (Fig. $2 C)$. Statistical analysis of the waveform of the AD coupling obtained at depolarized potentials showed a marked increase in the SD at the falling phase of the response when compared with those obtained at resting potential (Fig. 2D). Because in contrast to chemical synapses electrical transmission is not probabilistic in nature, the observed fluctuations could represent the involvement of a voltage-dependent amplifying mechanism.

We next examined the time dependence of the voltage-dependent enhancement of $\mathrm{AD}$ coupling by measuring the amplitude of this potential at different intervals after the onset of a $50 \mathrm{msec}$ depolarizing pulse (Fig. 3A). Although never reaching the values observed at resting potential, the amplitude of the AD coupling decreased with interval duration and reached plateau for intervals $>15 \mathrm{msec}$ (Fig. $3 A, B$ ). Strikingly, the voltage dependence of the $\mathrm{AD}$ coupling at the $40 \mathrm{msec}$ interval showed a linear relationship with proportional changes at both sides of the resting potential, lacking the characteristic steep enhancement between the resting potential and the threshold of the cell observed at the onset of depolarizing pulses

(Fig. 3C). When fit with a straight line, the slope of this relationship averaged $0.09( \pm 0.015 \mathrm{SEM} ; n=12)$ and was indistinguishable $(p>0.6)$ from the estimated linear component $\left(k_{1}\right)$ of the voltage dependence at the onset of the same depolarizing pulse (Fig. 3C). Thus, the time dependence of the component represented by the $k_{2}$ constant confirms the existence of the two independent mechanisms proposed by quantitative analysis of the voltage dependence and suggests the involvement of an amplifying mechanism that inactivates-deactivates over time. Consistent with this interpretation, the enhanced responses at the onset of the depolarizing pulse exhibited different kinetics than those observed at both the $40 \mathrm{msec}$ interval and the resting potential. This property is illustrated in Figure $3 D$, in which the averaged amplitudes of the AD coupling obtained at the onset, $40 \mathrm{msec}$, and resting potential $[4.11 \pm 0.24 \operatorname{SEM}(n=35), 2.43 \pm 0.22$ $\operatorname{SEM}(n=38)$, and $1.57 \pm 0.12 \operatorname{SEM}(n=38) \mathrm{mV}$, respectively] are plotted against the time constants of their respective decays $[1.38 \pm 0.16 \operatorname{SEM}(n=35), 0.56 \pm 0.04 \operatorname{SEM}(n=38)$, and $0.73 \pm 0.05 \operatorname{SEM}(n=18) \mathrm{msec}$, respectively].

\section{Voltage-dependent enhancement of AD coupling is sensitive to QX-314 and TTX}

Both the voltage sensitivity and membrane potential range of the time-sensitive $\left(k_{2}\right)$ component are consistent with those of a subthreshold $\mathrm{Na}^{+}$current (Crill, 1996). Therefore, we tested the effect of intracellularly injected QX-314 (which blocks $\mathrm{Na}^{+}$ channels) on the amplitude of the AD coupling obtained at different membrane potentials (Fig. 4A). The amplitude of the depolarization-enhanced $\mathrm{AD}$ coupling was reduced after the injection of QX-314 ( $~ 60 \%$ in the example of Fig. $4 A$ ), whereas that recorded at the resting potential remained, in this case, un- affected. The amplitude of the AD coupling obtained at depolarized and resting potentials after QX-314 injection averaged 46\% $( \pm 4$ SEM $)$ and $81.3 \%( \pm 10$ SEM $)$ of those obtained at the same potential before QX-314, respectively $(n=14)$. These changes occurred within a time window in which the fast action potentials of the afferents remained essentially unaffected (Fig. $4 B$, inset). The fact that depolarization-enhanced potentials were differentially affected by QX-314 excludes the possibility that the observed reduction was caused either by a decrease in gap junctional conductance or by diffusion of this drug to the M-cell to affect the antidromic spike generation, the source of the coupling. This finding was confirmed by performing simultaneous extracellular recordings of the M-cell antidromic spike during QX-314 injections (data not shown). Thus, although the diffusion of small or ineffective amounts of QX-314 to the M-cells cannot be ruled out, our data are consistent with previous reports (Logan et al., 1996; Mann-Metzer and Yarom, 1999) indicating that QX-314 is impermeable through neuronal gap junctions.

The slope of the relationship between the AD coupling amplitude and the membrane potential after QX-314 lacked the characteristic steep voltage dependence observed between the resting potential and threshold of the afferent (Fig. $4 B$ ). When fitted with a straight line, the slope of the relationship obtained after QX-314 resembled that of the $k_{1}$ linear component of the relationship obtained earlier in the recording, during control conditions (Fig. $4 B)$. The slope averaged $0.086( \pm 0.014$ SEM; $n=5)$, and it was not significantly different from the $k_{1}$ in control conditions $(p>$ $0.8)$, suggesting that QX-314 selectively targeted the timedependent supralinear component of the voltage dependence. Accordingly, the difference between the values in control and after QX-314 (Fig. 4C) could be fit with an exponential function 

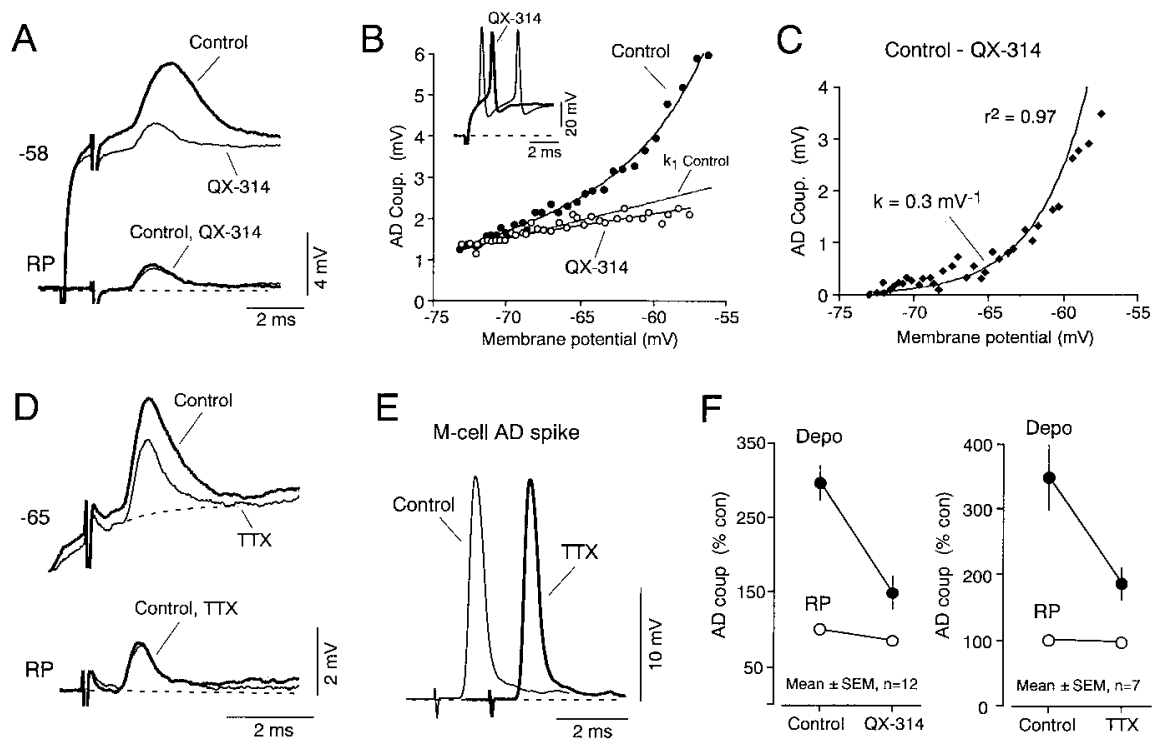

Figure 4. Voltage-dependent enhancement of AD coupling is blocked by both QX-314 and TTX. A, Superimposed traces obtained at resting potential $(-67 \mathrm{mV}$ ) and $-58 \mathrm{mV}$ recorded $5 \mathrm{~min}$ (control) and $25 \mathrm{~min}$ (QX-314) after the penetration of the cell with an electrode containing $50 \mathrm{~mm}$ QX-314. Note the contrast between the marked reduction in the amplitude of the coupling recorded at the depolarized potential and the lack of change of the response obtained at resting potential. $B$, Quantitative relationship between the $A D$ coupling and the membrane potential in the same fiber $5 \mathrm{~min}$ (control, filled circles) and $25 \mathrm{~min}$ after the penetration with the QX-314-containing electrode (QX-314, empty circles). The relationship observed after QX-314 is similar to the $k_{1}$ component calculated early in the recording ( $k_{1}$ control). Inset, Suprathreshold depolarizing pulses obtained before and after intracellular injection of QX-314. Blockade of the voltage-dependent enhancement of AD coupling occurs, whereas spikes are still not significantly affected by QX-314. C, Plot of the difference between the quantitative relationships obtained at control and after the QX-314 effect in the same experiment. The component removed by QX-314 was quantitatively similar, when fitted with an exponential function, to the $k_{2}$ component calculated earlier in the recording $\left(k_{2}=0.21 \mathrm{mV}^{-1}\right)$. D, TTX blocks the voltagedependent enhancement of AD coupling. Superimposed traces obtained at resting potential ( $R P,-71 \mathrm{mV}$ ) and near threshold $(-65)$ in control and after topical application of TTX (1 $\mu \mathrm{M})$ in the VIIIth nerve. As with QX-314, note the marked reduction in the amplitude of the coupling recorded at the depolarized potential, with no significant change of the response obtained at resting potential. $E$, The antidromic action potential of the M-cell remained unchanged at the time that the voltage-dependent enhancement of AD coupling was already suppressed. Traces illustrate the M-cell antidromic action potential recorded simultaneously with the afferent before and 10 min after the application of TTX. F, Plot summarizes the data obtained for the QX-314 and TTX experiments. The mean amplitude of the AD coupling potential at resting potential (RP) and $-60 /-65 \mathrm{mV}$ (Depo) are plotted before and after QX-314 (left) and TTX (right) as percentages of their amplitude at resting potential during control conditions (bars represent SEM; not visible for responses at resting potential).

with a constant that averaged $0.24 \mathrm{mV}^{-1}( \pm 0.033 \mathrm{SEM} ; n=5)$, a value that was not significantly different from the $k_{2}$ component estimated in control conditions $(p>0.2)$

Because QX-314 has been reported to have nonspecific actions on other than $\mathrm{Na}^{+}$channels, we tested the effect of extracellular application of TTX, which specifically blocks $\mathrm{Na}^{+}$channels, on the amplitude of the AD coupling obtained at different membrane potentials. Because the application of TTX would ultimately lead to a reduction of the antidromic spike of the M-cell (the source of the coupling), these experiments were performed while simultaneously recording from this neuron (Fig. $4 E$ ). As with QX-314, we observed a large decrease in the amplitude of the $\mathrm{AD}$ coupling at depolarized potentials, whereas those obtained at resting potential remained essentially unaffected (Fig. 4D). Overall, the reduction of the amplitude of the $\mathrm{AD}$ coupling obtained at depolarized and resting potential after TTX was quite similar to those observed after QX-314, averaging 50\% ( \pm 6 SEM) and 93\% $( \pm 9$ SEM) of their values in control conditions, respectively $(n=$ $8 ; p<0.0005)$. The $\mathrm{M}$-cell antidromic spike remained unaffected (Fig. $4 E$ ), averaging $96 \%$ of control ( \pm 7 SEM; $n=7 ; p>0.6$ ) at the time during which these changes of $\mathrm{AD}$ coupling amplitude were observed (we generally observed a delay of $\sim 30$ min before the M-cell antidromic spike was affected because TTX was ap-

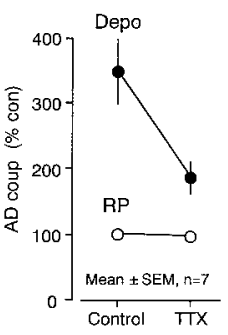

plied topically on the nerve entry point, and the somata of this cell lies deep within the medulla). As expected, the slope of the voltage-dependent relationship obtained after TTX was linear and similar to that obtained after QX-314 and lacked the characteristic steep voltage dependence observed between the resting potential and threshold of the afferent (data not shown).

Figure $4 F$ summarizes the data obtained for the QX-314 and TTX experiments; the amplitudes of the AD coupling at resting and depolarized potentials before and after the action of these drugs are plotted as percentages of the amplitude at resting potential during control conditions. Neither QX-314 nor TTX reduced the amplitude of the depolarizationenhanced AD couplings to the values observed at resting potential, consistent with the existence of an additional mechanism ( $k_{1}$ component) that is responsible for $\sim 20 \%$ of the amplification observed during depolarization. Finally, both intracellular QX-314 and extracellular TTX ultimately led to a profound reduction of the amplitude of the action potential of the afferents ( $\sim 70 \%$ decrease $)$ that was identical to that observed when $\mathrm{Na}^{+}$was replaced by tetramethyl ammonium in the extracellular perfusion solution (data not shown), confirming that both drugs targeted $\mathrm{Na}^{+}$channels.

\section{Slow-inactivating TTX-sensitive membrane conductance underlies voltage dependence of $\mathrm{AD}$ coupling}

To test for the existence of a subthreshold voltage-sensitive $\mathrm{Na}^{+}$conductance, the membrane properties of the afferents were examined by measuring their current-voltage relations without superimposed coupling potentials. The membrane responses to current steps were similar in all studied fibers $(n=16)$, and one set of these responses is illustrated in Figure 5A. For a given size depolarizing current pulse, we found a nonlinear voltage response that was maximal within $\sim 2 \mathrm{msec}$ of the pulse onset and then rapidly decayed to a steady-state value. The magnitude of this initial response was not proportional to the injected current and was more obvious for near-threshold depolarizations (Fig. 5A). The steady-state late response was a linear function of the polarizing current for depolarizing and hyperpolarizing pulses (Fig. 5B, filled circles), but the early responses exhibited the previously mentioned nonlinearity in the depolarizing direction, taking the form of an apparent increase in membrane slope resistance (Fig. $5 B$, open circles). This initial nonlinear response to depolarizing pulses was reduced by TTX application (Fig. 5C), averaging 31\% of control ( \pm 13 SEM; $n=4)$. As a result of TTX application, the $I-V$ relationship became linear, undistinguishable from that obtained at steady state (Fig. 5D). To demonstrate that this TTXsensitive subthreshold membrane response is the mechanism responsible for the amplification of $\mathrm{AD}$ coupling during depolarization, we compared the time courses of both phenom- 

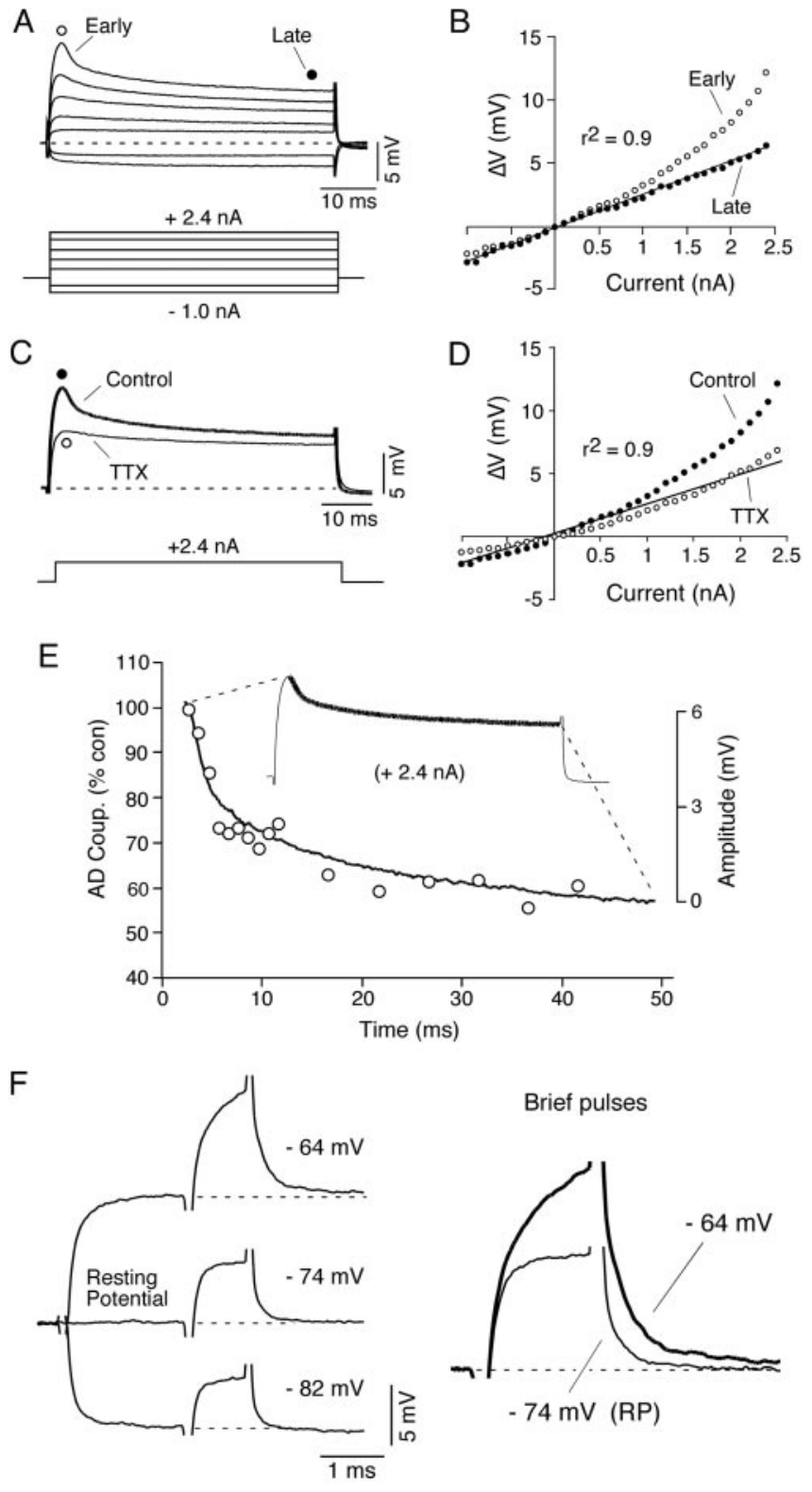

Figure 5. TTX-sensitive nonlinear membrane conductance contributes to the voltage dependence of $A D$ coupling. $A$, Voltage responses to seven current pulses ( 50 msec duration, -1 to $+2.4 \mathrm{nA}$; below). Note the progressively larger transient membrane response (open circle) at the pulse onset. $B$, Voltage ( $\Delta V$; ordinate) - current (abscissa) relation obtained in the same afferent fiber, measured at 2 (open circles) and $48 \mathrm{msec}$ (filled circles). The voltage-current relation is the same at both times for hyperpolarizations, and the membrane behaves linearly in the steady state (voltage responses at $\sim 50$ msec were fit with a straight-line function; solid line). At pulse onset, however, the V-/relationship exhibits a nonlinearity in the form of an apparent increase in membrane slope resistance with depolarization. C, Effect of $10 \mu \mathrm{m}$ TTX on the membrane voltage responses. Superimposed traces represent the voltage responses to a pulse of $+2.4 \mathrm{nA}$ (below), before (Control) and $15 \mathrm{~min}$ after application of TTX.D, Voltage $(\Delta V)$ - current relation obtained in the same afferent fiber at the onset of the pulse before (Control, filled circles) and after (empty circles) TTX application. Voltage responses after TTX were fit with a straight-line function (solid line). Note the disappearance of the nonlinearity observed at the onset of the pulse. $E$, Nonlinear membrane properties match the time dependence of the voltage-dependent enhancement of $A D$ coupling. The decay of the membrane voltage response to $\mathrm{a}+2.4 \mathrm{nA} / 50$ msec pulse is illustrated superimposed to the amplitudes of the $\mathrm{AD}$ coupling obtained at different intervals after the onset of a 50 msec depolarizing pulse of lesser magnitude (open circles; same data shown in Fig. 3B). F, Voltage-dependent changes can be replicated on a brief depolarizing current pulse injected through the presynaptic recording electrode. The depolarization produced at resting potential by a brief current pulse (1 msec duration; $0.5 \mathrm{nA}$ ) was dramatically enhanced by depolarization and slightly decreased by hyperpolarization $( \pm 0.9 \mathrm{nA})$. Observe the increased rise time and decay of the depolarization-enhanced response, which resembled those observed for the $A D$ coupling (compare with Figs. 1B,2A). ena. As shown superimposed in Figure 5E, the decay of the membrane response to a near-threshold depolarizing pulse closely followed the time course of the above-mentioned time dependence of AD coupling amplitude (see above). Accordingly, the amplitude of AD coupling at the $40 \mathrm{msec}$ interval of a $50 \mathrm{msec}$ depolarizing pulse was not significantly affected by QX-314, averaging $80 \%$ of control ( \pm 13 SEM; $n=10 ; p=0.3$ ). Such a small (although not significant) reduction in amplitude after QX-314 at the $40 \mathrm{msec}$ interval is ascribable to a parallel reduction in this coupling observed at resting potential (see above; it averaged $81.3 \%, \pm 10$ SEM, of control; $n=14$; difference not significant; $p=0.33)$. This observation suggests that large AD couplings could activate at resting potential a significant portion of this amplifying current (see next section).

If this subthreshold membrane conductance, but not the voltage-dependent properties of the gap junction channels, is responsible for most of the amplification of electrical coupling, the changes in the $\mathrm{AD}$ coupling should be replicated at different membrane potentials by injection of a current pulse through the afferent electrode. That is, depolarization and hyperpolarization of the afferent should then have the same effect on the potential produced by a constant current pulse as it does on the $\mathrm{AD}$ coupling potential. To directly demonstrate that this membrane property is responsible for amplification of the $\mathrm{AD}$ coupling, we asked whether voltage-dependent changes could be replicated on a brief depolarizing current pulse ( $1 \mathrm{msec}$ duration) injected through the presynaptic recording electrode (Fig. $5 F$ ). We found that the depolarization produced at resting potential by the brief current pulse was dramatically enhanced by depolarization (pulse averaged $175.5 \% \pm 9.4$, SEM, of control; $n=5$ ) and slightly decreased by hyperpolarization (pulse averaged $82.6 \% \pm$ 9.4, SEM, of control; $n=5$ ). Furthermore, depolarizationenhanced brief pulses had kinetic changes (increased rise time and decay) (Fig. 5F, right) that resembled those observed for the $\mathrm{AD}$ coupling and exhibited a similar time dependence (data not shown).

Subthreshold $\mathrm{Na}^{+}$currents are slowly inactivating and generally opposed by repolarizing potassium $\left(\mathrm{K}^{+}\right)$conductance(s) (Crill, 1996). Both the time dependence of the amplification and kinetic characteristics of the depolarization-enhanced $\mathrm{AD}$ coupling potentials, which are generally followed by a slight hyperpolarization $(\sim 0.5-1 \mathrm{mV}$ at $-65 \mathrm{mV}$ membrane potential) (Fig. $6 \mathrm{~A}$, arrow), suggested the involvement of a subthreshold repolarizing response. Therefore, we tested the effect of the intracellular injection of a combination of $\mathrm{K}^{+}$channel blockers $(0.5 / 1.0$ м TEA-Cl, 0.075/0.15 м 4-aminopyridine, $1 / 2$ м CsCl; see Materials and Methods) on the $\mathrm{AD}$ coupling and membrane responses to depolarizing steps. We found that the injection of $\mathrm{K}^{+}$channel blockers prolonged the decay of the $\mathrm{AD}$ coupling (Fig. $6 B$ ) and the initial voltage response to a depolarizing pulse (Fig. $6 \mathrm{C}$ ). Remarkably, the time dependence of the $\mathrm{AD}$ coupling amplification was no longer observed (Fig. $6 D$ ). Figure $6 E$ illustrates the amplitude of $\mathrm{AD}$ coupling potentials obtained at different intervals after the onset of a 50 msec depolarizing pulse, in the absence (filled circles) and presence (empty circles) of $\mathrm{K}^{+}$channel blockers in the recording electrode for five and seven experiments, respectively. In contrast with that observed in control conditions (Fig. $5 B$ ), the $V-I$ relationship after injection of $\mathrm{K}^{+}$channel blockers exhibited at the end of $50 \mathrm{msec}$ pulses a nonlinearity in the depolarizing direction in the form of an apparent increase in membrane slope resistance (Fig. $7 A, B$, filled circles). This nonlinearity was sensitive to extracellular application of TTX $(10 \mu \mathrm{M})$ (Fig. $7 B$ ), which linearized the membrane response (Fig. $7 C$, 
A
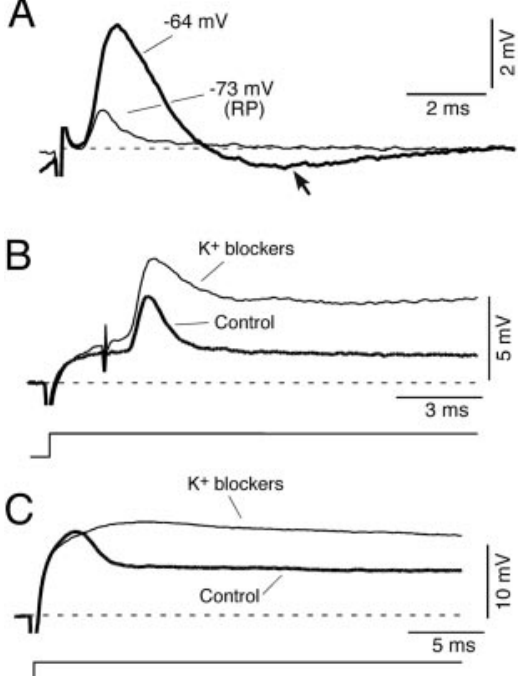

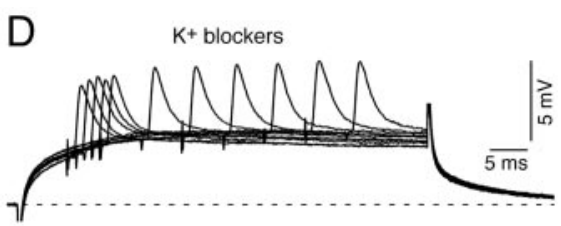

E

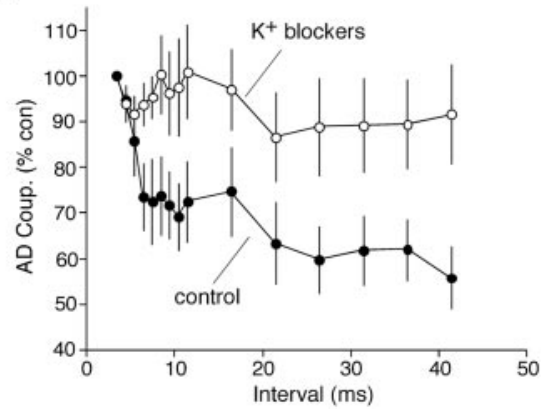

Figure 6. $\mathrm{K}^{+}$channel blockers abolished the time dependence of voltage-dependent enhancement of $\mathrm{AD}$ coupling. $A$, Superimposed traces illustrate the antidromic coupling potential obtained at resting potential (RP, $-73 \mathrm{mV}$ ) and at $-64 \mathrm{mV}$, at the onset of a depolarizing pulse. The depolarization-enhanced $A D$ coupling is generally followed by a small hyperpolarization (arrow), suggesting the involvement of repolarizing conductances. $B$, Superimposed traces illustrate the amplitude and time course of the AD coupling during a depolarization produced by current injection $(0.4 \mathrm{nA}) 1 \mathrm{~min}$ (Control) and $15 \mathrm{~min}$ after the penetration of the afferent with a recording solution containing a combination of $\mathrm{K}^{+}$channel blockers ( $1.0 \mathrm{~m}$ TEA-Cl, $0.15 \mathrm{~m}$ 4-aminopyridine, $2 \mathrm{~m} \mathrm{CsCl).} \mathrm{C,} \mathrm{Voltage} \mathrm{responses} \mathrm{to} \mathrm{depolarizing}$ current steps of $0.8 \mathrm{nA}$, immediately (control) and $15 \mathrm{~min}$ after ( $\mathrm{K}^{+}$blockers) penetration of the fiber with an electrode containing a combination of $\mathrm{K}^{+}$channels blockers. $D, \mathrm{~K}^{+}$channel blockers eliminate the time dependence of the voltage-dependent enhancement of $A D$ coupling. Superimposed traces show the $A D$ coupling at different intervals from the onset of a $0.5 \mathrm{nA}$ depolarizing pulse. $E$, Graph summarizes the amplitude of the AD coupling (ordinate) at different intervals (abscissa) after the onset of a 50 msec depolarizing pulse for seven different fibers (open circles). The amplitudes of $A D$ couplings obtained in the absence of $\mathrm{K}^{+}$channel blockers in the recording solution are superimposed (filled circles; same data as illustrated in Fig. 3B). Bars represent \pm SEM.

empty circles). Thus, the experiments using $\mathrm{K}^{+}$channel blockers revealed the presence of a slowly inactivating subthreshold $\mathrm{Na}^{+}$ conductance that is counterbalanced by a delayed repolarizing potassium conductance(s), which is responsible for the observed time dependence of the voltage-dependent amplification of the AD coupling.

Taken together, our results indicate that a subthreshold TTXsensitive noninactivating or slowly inactivating $\mathrm{Na}^{+}$conductance is responsible to a large extent for the amplification of $\mathrm{AD}$ coupling and is opposed by delayed repolarizing $\mathrm{K}^{+}$conductance(s), and this interplay closely reproduces the waveform of the $\mathrm{AD}$ coupling obtained at the resting potential (Fig. 7D). Such remarkable resemblance with the waveform of the AD coupling at resting potential is demonstrated by the fact that the changes in amplitude and area of the depolarization-enhanced response for the example illustrated in Figure $7 D$ were very similar (3.5- and 4.5-fold increase, respectively).

\section{Nonlinear amplification of electrical coupling at resting potential}

We showed that because of the activation of a subthreshold $\mathrm{Na}^{+}$ current the coupling coefficient for antidromic impulses from the M-cell to each club ending is enhanced by depolarization of the terminal of that ending. Such nonlinearity of the AD coupling coefficient could also exist at resting membrane potential if this signal were large enough to activate a significant fraction of the amplifying current, which could occur when gap junctional conductances were greater. To test this hypothesis we took advantage of the fact that the amplitude of the $\mathrm{AD}$ coupling potential between neighboring club endings dramatically varies in size and asked whether larger potentials were differentially affected by intracellular injection of QX-314. The variability in amplitude of $\mathrm{AD}$ coupling potentials reflects the large variation in gap junctional conductance observed among these terminals (Smith and Pereda, 2003) that is dynamically regulated by the activity of their colocalized glutamatergic synapses (Yang et al., 1990; Pereda and Faber, 1996; Pereda et al., 1998, 2003b; Smith and Pereda, 2003). By recording presynaptically from these afferents, we found that the amplitude of the AD coupling at resting potential was reduced by QX-314 injection and that the magnitude of the reduction was positively correlated with the amplitude of the coupling potential in control conditions (Fig. 8A) $(n=$ 12). The differential susceptibility of larger AD coupling potentials to QX-314 can account for the slight overall reduction of this signal observed at resting potential (see above) (Fig. $4 F$ ).

To demonstrate that larger, QX-314sensitive AD coupling potentials corresponded to higher conducting junctions, we compared coupling coefficients between neighboring terminals within the same dendrite. For this, we obtained in one fish multiple paired recordings between single afferent fibers and the same M-cell dendrite and plotted the amplitude of the orthodromic coupling potentials (the potential recorded in the $\mathrm{M}$-cell corresponding to the presynaptic spike) (Fig. $8 \mathrm{~B}$ ) as an indicator of the degree of conductance of the junctions in each particular terminal versus the amplitude of their corresponding AD couplings (Fig. $8 \mathrm{~B}$ ). We found that this relationship was not linear because afferents that showed larger orthodromic potentials (and presumably higher conducting junctions) exhibited $\mathrm{AD}$ couplings that were bigger than those expected from the projection of a linear relationship obtained using terminals that exhibited small orthodromic potentials (Fig. $8 B$, bottom, dotted line).

\section{Amplification of retrograde coupling operates under physiological conditions}

We used the $\mathrm{AD}$ coupling to explore the mechanisms underlying the voltage dependence of retrograde electrical transmission but argued that such mechanisms could operate during coactivation of the afferents, because signals would be large enough to activate a significant fraction of the subthreshold $\mathrm{Na}^{+}$current in the terminals. To demonstrate that this amplification operates under these conditions, we tested the effect of QX-314 on the amplitude of the retrogradely transmitted coupling potential attributable to the dendritic depolarization produced by the activation of a population of these afferents; that is, the characteristic intradendritically recorded mixed, electrical, and chemical, synaptic potential in response to VIIIth nerve stimulation (Fig. 9A) (Furshpan, 1964) can be recorded simultaneously as a coupling potential in nearby terminals for which the stimulus strength is subthreshold (Fig. 9B, VIIIth N. coup) (Pereda et al., 1995). This coupling potential has been shown to have voltage-dependent characteristics identical to those of the AD coupling (Pereda et al., 1995) and is capable (when a sufficient number of afferents are recruited by 


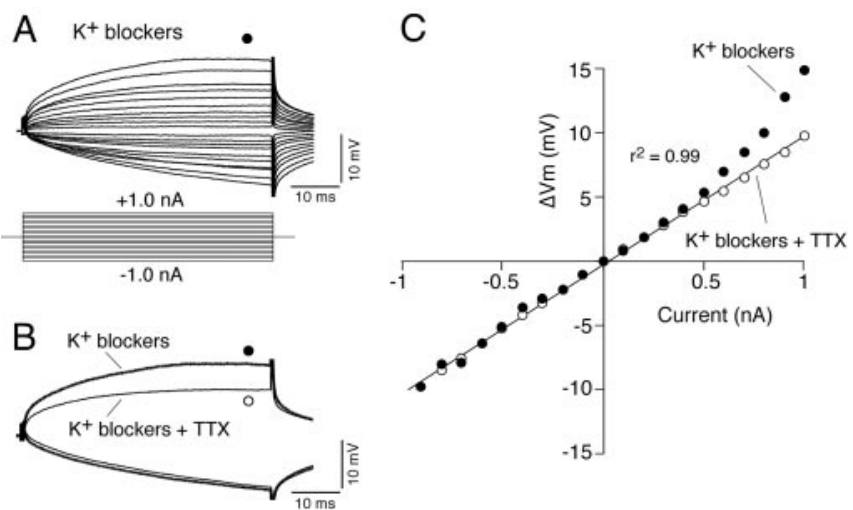

D

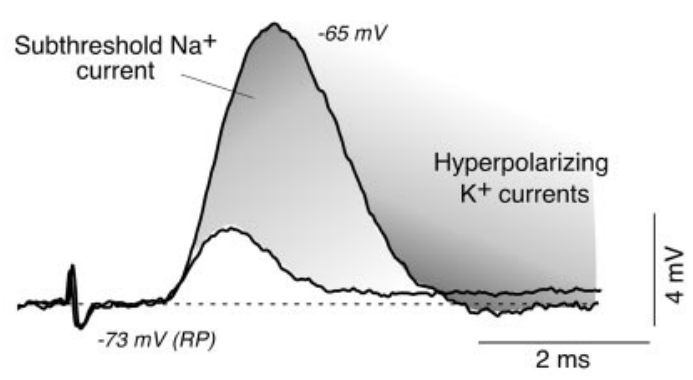

Figure 7. Involvement of a persistent $\mathrm{Na}^{+}$current in the voltage-dependent enhancement of the $\mathrm{AD}$ coupling. $A$, Voltage responses to depolarizing and hyperpolarizing current pulses (50 msec duration; -1 to $+1 \mathrm{nA}$ ) after intracellular injection of $\mathrm{K}^{+}$channels blockers. Note the late apparent increase in the resistance of the cell (inward rectification) with progressively stronger depolarizing pulses (filled circles). $B$, Voltage responses to depolarizing and hyperpolarizing current pulses $( \pm 1 \mathrm{nA})$ obtained in the same afferent before and after the application of TTX $(10 \mu \mathrm{M})$. TTX blocks the apparent increase in membrane resistance observed at the end of the depolarizing pulse induced by the injection of $\mathrm{K}^{+}$channels blockers. $C$, Voltage $\left(\Delta V_{\mathrm{m}}\right.$, ordinate) - current (Current, abscissa) relationship obtained in the same afferent before (filled circle) and after (open circle) the application of TTX. The apparent increase in input resistance (late inward rectification) is abolished by topical application of TTX. D, Enhancement of AD coupling results from the interplay between a subthreshold $\mathrm{Na}^{+}$current and repolarizing $\mathrm{K}^{+}$ conductances. Superimposed traces illustrate the AD coupling potential obtained at resting potential (RP; $-73 \mathrm{mV}$ ) and at a depolarized potential ( -66 ; same experimentillustrated in Fig. 2A). Depolarization progressively activates a subthreshold $\mathrm{Na}^{+}$current (graded area) that is deactivated by contrasting voltage-sensitive $\mathrm{K}^{+}$conductance(s) (darker graded area).

adjusting VIIIth nerve stimulation) of eliciting an action potential in the recorded afferent ("backfiring") (Pereda et al., 1995). For the experiments reported here, we adjusted the amplitude of the VIIIth nerve coupling to be at the threshold of the cell, where this depolarization was able to occasionally elicit spikes in the recorded afferent (Fig. 9B, inset); this allowed us to monitor the size of the coupling potential as well to test the potential role of its amplification in recruiting subthreshold afferents. We found that the amplitude of this response was greatly attenuated by intracellular injection of QX-314 (Fig. 9B), averaging 53.9\% of the values obtained at control ( $\pm 8 \%$ SEM; $n=5)$, and was no longer able to backfire the afferent, suggesting that amplification of retrograde transmission takes place during orthodromic activation of a population of afferent fibers. To demonstrate the existence of this amplification under more physiological conditions, we used natural stimulation in the form of brief sound clicks (Fig. 9A). These experiments were performed during "intraterminal" recordings (Pereda et al., 1998; Smith and Pereda, 2003) within a radius of $40-60 \mu \mathrm{m}$ from the lateral dendrite, localized by an initial penetration of that process, while monitoring the responses to natural stimulation delivered by a speaker located near the animal's
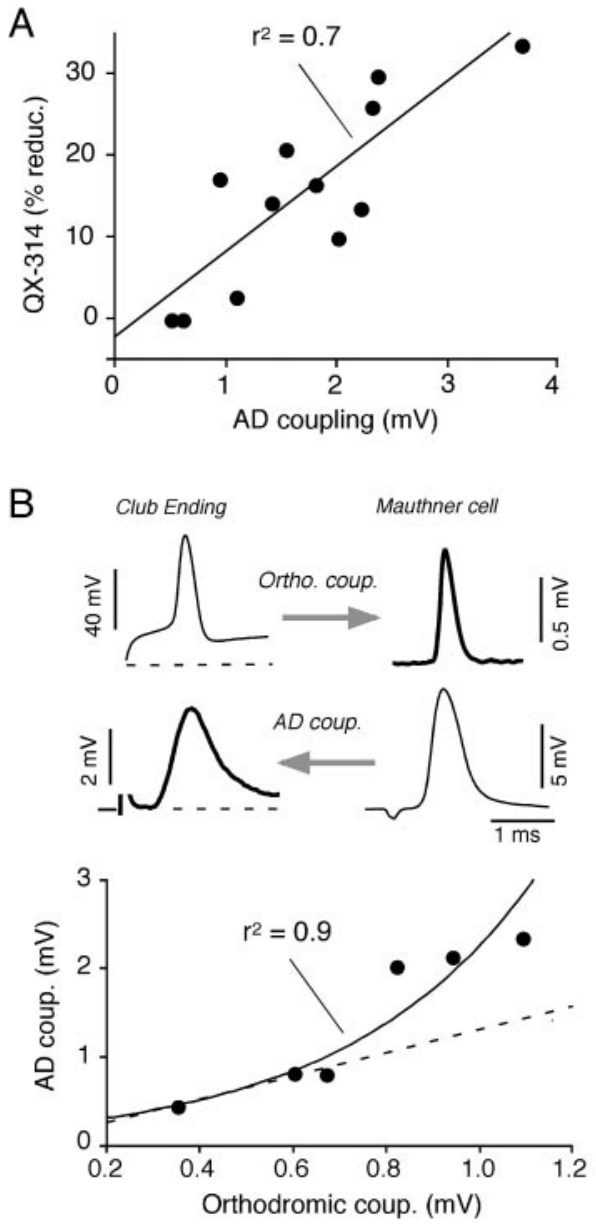

Figure 8. Nonlinear amplification of retrograde coupling at resting potential. A, Graph plots the amplitude of the $A D$ coupling potentials at resting potential in control conditions (abscissa) versus their respective reduction after intracellular injection of QX-314 (ordinate) expressed as percentage of amplitude in control $(n=13)$. B, Simultaneous presynaptic and postsynaptic recordings between club endings and the M-cell lateral dendrite (top) allow correlation between orthodromic and antidromic coupling potentials in the same terminal. Graph (bottom) illustrates the relationship between the amplitude of orthodromic (abscissa) and antidromic (ordinates) coupling potentials in six terminals, obtained while recording from the same dendrite. The dotted line represents the linear relationship between orthodromic and antidromic couplings estimated using the three terminals that exhibit small orthodromic coupling potentials with, presumably, lower conducting junctions. Club endings that exhibit larger orthodromic potentials (presumably higher conducting junctions) showed $A D$ couplings that were bigger than those expected from the relationship obtained in low-conducting terminals.

head (500 $\mu$ sec duration click). This recoding site, in the vicinity of the lateral dendrite of the M-cell, is electrotonically distant from the hair cell side of the afferent and therefore rules out a potential contamination of the recordings with auditory evoked synaptic potentials. Figure $9 C$ illustrates the intradendritic response to this brief auditory stimuli (top) and the coupling, obtained in sequential recordings, in one neighboring terminal for which the stimulus strength was subthreshold (bottom). This coupling was also suppressed by QX-314 and averaged 59.6\% of control (range, 58.1-62.2\%; $n=4$ ), indicating that amplification of retrograde coupling by the subthreshold $\mathrm{Na}^{+}$current occurs under physiological conditions. Unfortunately, we were not able to backfire subthreshold recorded terminals with this soundevoked coupling potential because of the impossibility of recruiting enough afferents to generate a sizable coupling potential without directly activating the recorded one. This is attributable to the fact that sound stimulation depends on the physiological 
A
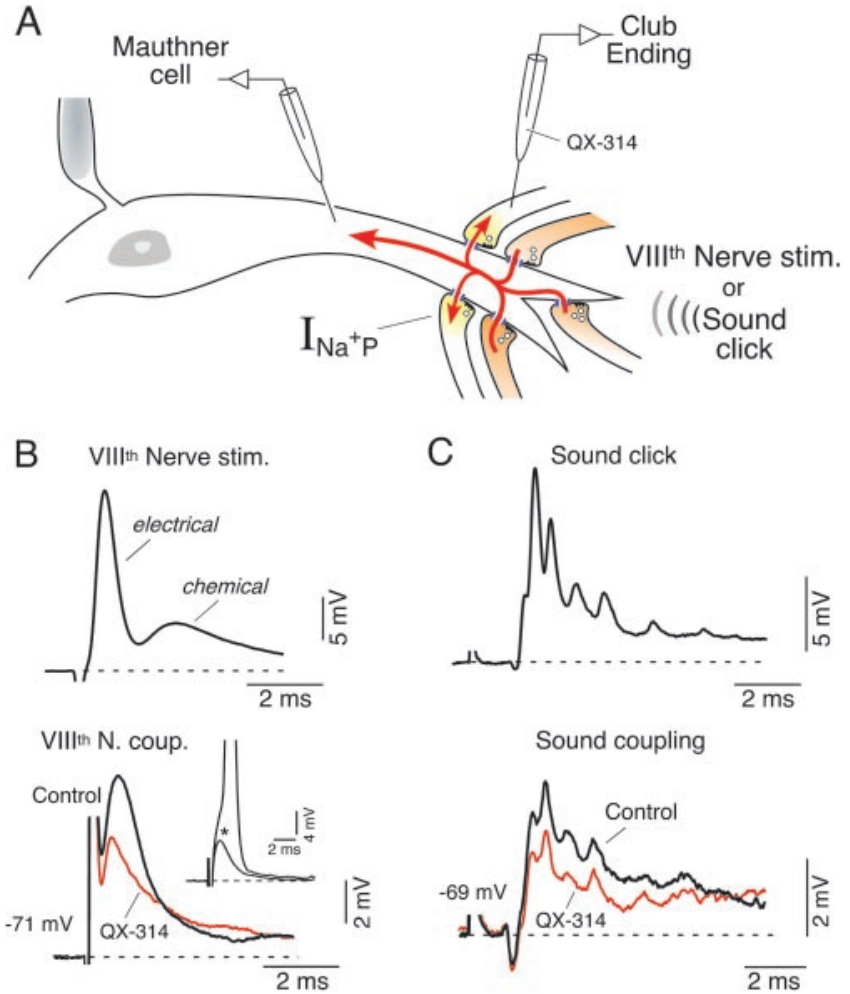

Sound coupling
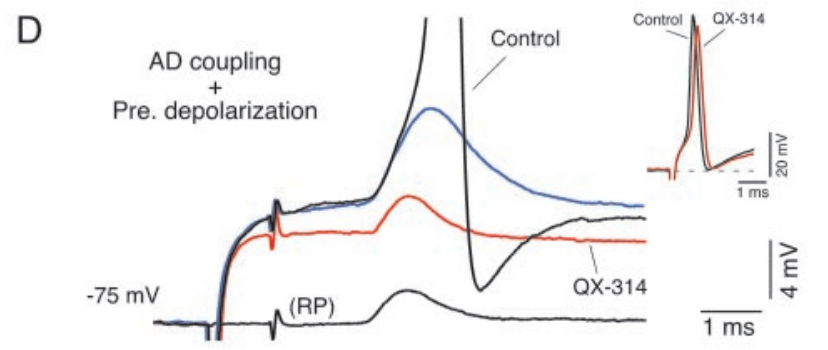

Figure 9. Voltage-dependent enhancement of retrograde electrical coupling operates under physiological conditions. $A$, Dendritic synaptic potentials (Mauthner cell) evoked by suprathreshold electrical or natural stimulation of VIllth nerve afferents $(B, C$, top traces; dark orange afferents; VIIIth Nerve stim. and Sound click) can be recorded as coupling potential, in neighboring, subthreshold terminals (yellow terminals, club ending; bottom traces in $B$ and $C$, respectively). $I_{\mathrm{Na}+\mathrm{P}}=$ persistent (subthreshold) $\mathrm{Na}^{+}$current in the club endings. $B$, Mixed synaptic response (electrical and chemical) produced by extracellular electrical stimulation of the posterior branch of the VIIlth nerve (VIIIth Nerve stim.) evokes a retrograde coupling potential in a subthreshold terminal (bottom; VIIIth Nerve coup.). Inset, Amplitude of the VIIIth nerve coupling (asterisk) was adjusted to be at the threshold of the presynaptic afferent (truncated spike, $100 \mathrm{mV}$ ). Superimposed traces in the bottom panel represent the amplitude of this retrograde response obtained right after (control) and $15 \mathrm{~min}$ after the penetration of the terminal with an electrode containing a $50 \mathrm{~mm}$ solution of QX-314 (A, QX-314). C, Intradendritically recorded sound-evoked synaptic potential (Sound click; $500 \mu$ sec pulse) can also be recorded, intracranially, as a coupling potential in neighboring inactive terminals (bottom; Sound coup.). Superimposed traces represent the retrograde responses obtained right after (Control) and 5 min after the penetration of the synaptic terminal with an electrode containing QX-314. Note the reduction in amplitude of both retrograde coupling potentials observed after injection of QX-314 (red traces). D, Depolarization-enhanced retrograde coupling can recruit subthreshold afferents. The AD coupling was paired with a presynaptic depolarization (blue trace; compare the enhanced response with that obtained at resting potential; black trace; RP) at a membrane potential in which it was able to occasionally elicit action potentials in the presynaptic afferent (black trace; truncated spike, $100 \mathrm{mV}$ ). Intracellular injection of QX-314 (red trace) removes the amplification of $A D$ coupling (along with a small reduction in the depolarization produced in the current pulse), which is not longer capable of eliciting action potentials in the afferent. Inset, Effects of QX-314 occurred within a time window in which the fast action potentials of the afferents remained largely unaffected. Superimposed recordings show the amplitude of the action potential of the recorded afferent in control (black trace) and after QX-314 (red trace) at the time in which the changes in the AD coupling amplitude were observed. characteristics of the afferents, and therefore, unlike electrical stimulation, the number of activated afferents by auditory stimulation cannot be finely adjusted. Nevertheless, on the basis of the properties of the VIIIth nerve coupling (also produced by the orthodromic activation of auditory afferents), it is reasonable to assume that afferents might be similarly recruited by natural stimulation.

These data suggest that amplification of retrograde transmission by this current might play an essential physiological role in promoting the recruitment of subthreshold afferents during the activation of a population of these fibers. Because of its voltage dependence, such integrative property of this amplifying mechanism would be particularly relevant in afferents that were subliminally activated by the stimulus (i.e., depolarization did not reach threshold). To directly demonstrate this property, we paired the $\mathrm{AD}$ coupling with a presynaptic depolarization before and after the intracellular injection of QX-314 (the AD coupling was used instead of the VIIIth nerve coupling to avoid possible contamination by local responses produced by changes in axonal excitability after the nerve stimulation). The presynaptic depolarization (a current pulse delivered through the recording electrode) was adjusted for the AD coupling to be at the firing threshold of the cell (Fig. 9D); again, this allowed us to both visualize the coupling potential and test the potential role of its amplification in recruiting subthreshold afferents. We found that although under control conditions the depolarization-amplified AD coupling was able to elicit action potentials in the presynaptic afferent, this recruitment was blocked by QX-314, which dramatically reduced its amplitude (Fig. 9D, red trace). This phenomenon was observed in all of the explored fibers $(n=14)$ and occurred within a time window in which the fast action potentials of the afferents remained essentially unaffected (Fig. 9D, inset).

\section{Discussion}

Quantitative analysis, time dependence, and pharmacological evidence support the notion that voltage-dependent amplification of retrograde coupling at club endings is mediated by the combination of two independent mechanisms. One of these, and perhaps physiologically the most relevant, is responsible for $\sim 80 \%$ of the total amplification and reflects the gradual activation of a subthreshold membrane conductance with the characteristics of a persistent $\mathrm{Na}^{+}$current (Crill, 1996). That is, the voltage sensitivity $\left(0.42 \mathrm{mV}^{-1}\right)$, membrane potential activation range $(10-15$ $\mathrm{mV}$ above resting potential), susceptibility to TTX and QX-314, and prolonged time course in the presence of $\mathrm{K}^{+}$channel blockers are typical of persistent $\mathrm{Na}^{+}$currents described in fish (Watanabe et al., 2000; Berman et al., 2001; Doiron et al., 2003) and mammalian neurons (Hotson et al., 1979; Llinás and Sugimori, 1980; Staftsrom et al., 1982; French and Gage, 1985; Mac Vicar, 1985; Staftsrom et al., 1985; French et al., 1990; for review, see Crill, 1996). Although persistent $\mathrm{Na}^{+}$currents represent a small $(\sim 1 \%)$ noninactivating fraction of the total $\mathrm{Na}^{+}$current, they have a significant functional impact because they are activated $\sim 10 \mathrm{mV}$ negative to the transient $\mathrm{Na}^{+}$current, where few voltage-gated channels are activated and neuron input resistance is high (Crill, 1996). As a result of this property, these subthreshold $\mathrm{Na}^{+}$currents play essential cellular roles in amplifying dendritric synaptic potentials, regulating repetitive firing, and producing depolarizing responses (for review, see Crill, 1996; Ogata and Ohishi, 2002). Persistent $\mathrm{Na}^{+}$currents have also been reported to be present in sensory axons (Kocsis and Waxman, 1983; Bowe et al. 1985; Honmou et al., 1994).

Thus, in contrast to other electrical synapses in which voltage- 
dependent changes of electrical coupling rely on properties of the gap junction channels themselves (Furshpan and Potter, 1959; Auerbach and Bennett, 1969; Giaume and Korn, 1983; Edwards et al., 1991), voltage-dependent amplification of electrical coupling in club endings depends largely on the activation of nonlinear properties of the nonjunctional membrane. Interestingly, whereas in other systems long-lasting amplification of electrical coupling by noninactivating subthreshold $\mathrm{Na}^{+}$currents allows synchronized firing within a time window larger than that predicted by the time course of the presynaptic action potential (Mann-Metzer and Yarom, 1999), the contrasting interaction of this current with repolarizing $\mathrm{K}^{+}$currents reproduces closely the waveform of the coupling recorded at resting potential. Such interplay with repolarizing currents may reflect a cellular adaptation of these auditory terminals, characteristic of the auditory system, that is designed to faithfully preserve acoustic timing information (Trussell, 1997). We cannot at the present time speculate on the identity of the $\mathrm{K}^{+}$conductance(s) involved in this phenomenon. Such identification requires further biophysical and pharmacological analysis.

\section{Intrinsic membrane properties contribute to bi-directional electrical communication}

Recent work shows that QX-314-sensitive currents, presumably mediated by $\mathrm{Na}^{+}$channels, are involved in the amplification of electrical coupling between cerebellar inhibitory interneurons (Mann-Metzer and Yarom, 1999) and hippocampal pyramidal cells (Schmitz et al., 2001). Both computer modeling (Traub, 1995) and experimental data (Mann-Metzer and Yarom, 1999) suggest that subthreshold amplification of electrical coupling by intrinsic membrane properties plays a pivotal role in promoting the synchronization of weakly coupled neuronal networks. Our results support the view of these authors that electrical synapses and intrinsic membrane properties interact to create a highly modifiable communication pathway (Mann-Metzer and Yarom, 1999).

In the case of the club endings, intrinsic membrane properties act unilaterally to ensure efficient retrograde communication from the M-cells to these presynaptic terminals. Electrical coupling in this system occurs between two heterologous cell types of dramatically different size and electrical properties. Despite the fact that electrical transmission would result, enhanced by the higher input resistance of the presynaptic endings, retrograde transmission is challenged by the geometrical and electrical properties of the $\mathrm{M}$-cell that favor the spread of depolarizations from the lateral dendrite (where these terminals are segregated) toward the soma of this cell (Fig. 9A). Voltage-clamp analysis of the $\mathrm{M}$-cell dendritic resting conductances revealed the presence of an inward $\mathrm{K}^{+}$rectifier that by increasing dendritic resistance during depolarizations acts to boost excitatory inputs (Faber and Korn, 1986). Although the boosting of dendritic synaptic inputs would result in some enhancement of retrograde communication, it has been proposed that the key functional role of this current is to facilitate the spread of excitatory currents to the remarkably low impedance soma $(\sim 115 \mathrm{k} \Omega$ ) (Fukami et al., 1964) by increasing the dendrite to soma transmission during depolarizations (Faber and Korn, 1986). The presence of the voltage-dependent amplifying mechanism in the presynaptic club endings described here would ensure the detection of relevant postsynaptic signals, compensating for the challenging electrical and geometrical conditions.

\section{Possible contribution of the junctional membrane}

Although the mechanism underlying the weaker voltage dependence (represented by the $k_{1}$ component) is not the focus of the present paper, we speculate that it likely reflects a voltagedependent property of the junctional membrane, given the absence of other presynaptic conductances that could underline this behavior (Pereda et al., 1995). An adequate study of the observed phenomenon would require simultaneous recordings under voltage-clamp conditions. This behavior could be transjunctional in origin, because a difference of $\sim 10 \mathrm{mV}$ exists between the resting potentials of both cells $(-70 \mathrm{mV}$ in the terminal and -80 in the $\mathrm{M}$-cell dendrite). In the crayfish, fast rectification of electrical coupling from the lateral and medial giant axons to the motor giant axon (Furshpan and Potter, 1959) is believed to be caused by a transjunctional voltage dependence maintained by a difference between the resting potentials of the involved cell, and the removal of this voltage difference restores electrical bidirectionality (Giaume and Korn, 1983). Coupling of cells expressing dissimilar connexins that form hemichannels of different gating polarities is one way to establish rectifying junctions (Barrio et al., 1991; Bennett and Verselis, 1992; Verselis et al., 1994), and in some cases asymmetry can be strongly modulated by small changes in difference of holding potentials (Bukauskas et al., 2002). Interestingly, connexin35 (O'Brien et al., 1998), the fish ortholog of the neuron-specific mammalian gap junction forming protein connexin36 (Condorelli et al., 1998), has been reported to be abundantly present at both sides in the gap junction plaques between club endings and the M-cell, suggesting that electrical transmission is mediated via homotypic gap junction channels (Pereda et al., 2003a). Although the presence of additional neuronal connexins cannot be ruled out, the nonlinear behavior of these junctions suggests that hemichannels of identical connexin composition could exhibit subtle functional differences on each side of the junction, as a result, for example, of posttranslational modifications. Indeed, it has been proposed that only postsynaptic hemichannels (M-cell side) are the target of regulation by protein kinases (Pereda et al., 1994, 1998).

\section{Functional significance}

Amplification of retrograde coupling allows club endings to be electrically coupled to each other through the lateral dendrite of the M-cell (Pereda et al., 1995). Such coupling may act as a mechanism of lateral excitation, enhancing (1) transmitter release when fibers are activated simultaneously (Smith and Pereda, 2003; Curti et al., 2004) and (2) the effectiveness of this input when only a portion of these fibers is active by synchronizing that afferent population and promoting the recruitment of new fibers that are close to threshold (Pereda et al., 1995). It is generally believed that patterns of lateral excitation play relevant physiological roles in amplifying the responses of sensory afferents tuned to qualitatively similar stimuli (Herberholz et al., 2002). In contrast to other examples, such as retinal cones (DeVries et al., 2002) and crayfish locomotor networks (el Manira et al., 1993), in which electrical synapses are located between the presynaptic neurons, club endings are electrically coupled to each other through the M-cell lateral dendrite. This coupling arrangement would explain why whereas in some systems junctional properties prevent the antidromic spread of postsynaptically originated currents (Furshpan and Potter, 1959; Auerbach and Bennett, 1969: Ringham, 1975; Edwards et al. 1991), physiological properties of the club endings actually promote this phenomenon. Finally, this phenomenon could also underlie other important sensory mechanisms, because backfiring of mormyromast affer- 
ents by retrograde electrical communication (also demonstrated in club endings) (Pereda et al., 1995) has been proposed to mediate a rapidly acting type of lateral inhibition (Slesinger and Bell, 1985). Interestingly, as in the Mauthner cell system, Herberholz et al. (2002) recently demonstrated that indirect coupling through the postsynaptic cell is important in recruiting unstimulated afferents in the crayfish escape circuit. The similarity of the two systems suggests that this mechanism is functionally relevant and might constitute a widespread strategy among circuits in which synchrony of afferents is important.

Thus, as a result of the presence of a subthreshold $\mathrm{Na}^{+}$current, the coupling coefficient from the Mauthner cell to the club endings is voltage dependent. Such enhancement can be activated by depolarization of the presynaptic terminal, by an increase in junctional conductance, or during large dendritic depolarizations. Because all of these conditions coexist when a population of these afferents is activated by strong acoustic signals, this current is likely to play an important functional role. That is, the synchronization that it promotes would act to enhance the synaptic response, increasing the probability of initiating an escape response.

Similar asymmetric amplification of electrical coupling by intrinsic membrane properties might also occur between mammalian cells. Most of the electrical coupling in mammalian neurons takes place at remote dendritic sites (Llinás et al., 1974; Peinado et al., 1993; De Zeeuw et al., 1995; Fukuda and Kosaka, 2000, 2003) between dissimilar tortuous neuronal processes in which geometry, despite the presence of bi-directional gap junction channels, might challenge efficient bi-directional communication. Unilateral or asymmetric amplification of weaker electrical coupling by intrinsic membrane properties in one of the coupled cells might act to promote synchronized neuronal activity, by ensuring bidirectional communication between neuronal dendritic processes of different size and shape.

\section{References}

Auerbach AA, Bennett MVL (1969) A rectifying synapse in the central nervous system of a vertebrate. J Gen Physiol 53:183-210.

Barrio L, Schuyna T, Bargiello TA, Xian Hu L, Roginski R, Bennett MVL, Nicholson B (1991) Gap junctions formed by connexin 26 and 32 alone and in combination are differently affected by applied voltage. Proc Natl Acad Sci USA 88:8410-8414.

Bartelmez GW (1915) Mauthner's cell and the nucleus motorius tegmenti. J Comp Neurol 25:87-128.

Bennett MVL (1966) Physiology of electrotonic junctions. Ann NY Acad Sci 137:509-539.

Bennett MVL (1977) Electrical transmission: a functional analysis and comparison with chemical transmission. In: Cellular biology of neurons, Vol I, Handbook of physiology. The nervous system (Kandel ER, ed) pp 357416. Baltimore: Williams \& Wilkins.

Bennett MVL, Verselis VK (1992) Biophysics of gap junctions. Semin Cell Biol 3:29-47.

Berman N, Dunn RJ, Maler L (2001) Function of NMDA receptors and persistent sodium channels in a feedback pathway of the electrosensory system. J Neurophysiol 86:1612-1621.

Bowe CM, Kocsis JD, Waxman SG (1985) Differences between mammalian ventral and dorsal spinal roots in response to blockade of potassium channels during maturation. Proc R Soc Lond B Biol Sci 224:355-366.

Bukauskas FF, Angele AB, Verselis VK, Bennett MV (2002) Coupling asymmetry of heterotypic connexin 45/connexin 43-EGFP gap junctions: properties of fast and slow gating mechanisms. Proc Natl Acad Sci USA 99:7113-7118.

Condorelli DF, Parenti R, Spinella F, Trovato Salinaro A, Belluardo N, Cardile V, Cicirata F (1998) Cloning of a new gap junction gene (Cx36) highly expressed in mammalian brain neurons. Eur J Neurosci 10:1202-1208.

Crill WE (1996) Persistent sodium current in mammalian central neurons. Annu Rev Physiol 58:349-362.
Curti S, Bennett MVL, Pereda A (2004) Co-activation of afferents facilitates transmitter release at mixed synapses on the Mauthner (M-) cell. Soc Neurosci Abstr, in press.

DeVries SH, Qi X, Smith R, Makous W, Sterling P (2002) Electrical coupling between mammalian cones. Curr Biol 12:1900-1907.

De Zeeuw CI, Hertzberg EL, Mugnaini E (1995) The dendritic lamellar body: a new neuronal organelle putatively associated with dendrodendritic gap junctions. J Neurosci 5:1587-1604.

Doiron B, Noonan L, Lemon N, Turner RW (2003) Persistent Na ${ }^{+}$current modifies burst discharge by regulating conditional backpropagation of dendritic spikes. J Neurophysiol 89:324-337.

Eaton RC, Lee RK, Foreman MB (2001) The Mauthner cell and other identified neurons of the brainstem escape network of fish. Prog Neurobiol 63:467-485.

Edwards DH, Heitler WJ, Leise EM, Fricke RA (1991) Postsynaptic modulation of rectifying electrical synaptic inputs to the LG escape command neuron in crayfish. J Neurosci 11:2117-2129.

el Manira A, Cattaert D, Wallen P, DiCaprio RA, Clarac F (1993) Electrical coupling of mechanoreceptor afferents in the crayfish: a possible mechanism for enhancement of sensory signal transmission. J Neurophysiol 69:2248-2251.

Faber DS, Korn H (1986) Instantaneous inward rectification in the Mauthner cell: a postsynaptic booster for excitatory inputs. Neuroscience 19:1037-1043.

Frank K, Fuortes MGF (1956) Stimulation of spinal motoneurones with intracellular electrodes. J Physiol (Lond) 134:451-470.

French CR, Gage PW (1985) A threshold sodium current in pyramidal cells in rat hippocampus. Neurosci Lett 56:289-293.

French CR, Sah P, Buckett KJ, Gage PW (1990) A voltage-dependent persistent sodium current in mammalian hippocampal neurons. J Gen Physiol 95:1139-1157.

Fukami Y, Furukawa T, Asada Y (1964) Excitability changes of the Mauthner cell during collateral inhibition. J Gen Physiol 48:581-600.

Fukuda T, Kosaka T (2000) Gap junctions linking the dendritic network of GABAergic interneurons in the hippocampus. J Neurosci 20:1519-1528.

Fukuda T, Kosaka T (2003) Ultrastructural study of gap junctions between dendrites of parvalbumin-containing GABAergic neurons in various neocortical areas of the adult rat. Neuroscience 120:5-20.

Furshpan EJ (1964) Electrical transmission at an excitatory synapse in a vertebrate brain. Science 144:878-880.

Furshpan EJ, Potter DD (1959) Transmission at the giant motor synapses of the crayfish. J Physiol (Lond) 145:289-325.

Giaume C, Korn H (1983) Bi-directional transmission at the rectifying electrotonic synapse: a voltage-dependent process. Science 220:84-87.

Herberholz J, Antonsen BL, Edwards DH (2002) A lateral excitatory network in the escape circuit of crayfish. J Neurosci 22:9078-9085.

Honmou O, Utzschneider D, Rizzo M, Bowe, C Waxman SG, Kocsis JD (1994) Delayed depolarization and slow sodium currents in cutaneous afferents. J Neurophysiol 71:1627-1637.

Hotson JR, Prince DA, Schwartzkroin PA (1979) Anomalous inward rectification in hippocampal neurons. J Neurophysiol 42:889-895.

Kandel E, Tauc L (1966) Anomalous rectification in the metacerebral giant cells and its consequence for synaptic transmission. J Physiol (Lond) 183:287-304.

Kocsis J, Waxman SG (1983) Long-term regenerated nerve fibers retain sensitivity to potassium channel blocking agents. Nature 304:640-642.

Lasater E, Dowling JE (1985) Dopamine decreases conductance of the electrical junctions between cultured retinal horizontal cells. Proc Natl Acad Sci USA 82:3025-3029.

Lin JW, Faber DS (1988) Synaptic transmission mediated by single club endings on the goldfish Mauthner cell. I. Characteristics of electrotonic and chemical postsynaptic potentials. J Neurosci 8:1302-1312.

Llinás R, Sugimori M (1980) Electrophysiological properties of in vitro Purkinje cell somata in mammalian cerebellar slices. J Physiol (Lond) 305:171-195.

Llinás R, Baker R, Sotelo C (1974) Electrotonic coupling between neurons in the cat inferior olive. J Neurophysiol 37:560-571.

Logan SD, Pickering AE, Gibson IC, Nolan MF, Spanswick D (1996) Electrotonic coupling between rat sympathetic preganglionic neurons in vitro. J Physiol (Lond) 495:491-502.

Mac Vicar B (1985) Depolarizing prepotentials are $\mathrm{Na}^{+}$dependent in CA1 pyramidal neurons. Brain Res 333:378-381. 
Mann-Metzer P, Yarom Y (1999) Electrotonic coupling interacts with intrinsic properties to generate synchronized activity in cerebellar networks of inhibitory interneurons. J Neurosci 19:3298-3306.

Nakajima Y (1974) Fine structure of the synaptic endings on the Mauthner cell of the goldfish. J Comp Neurol 156:375-402.

O’Brien J, Bruzzone R, White TW, Al-Ubaidi MR, Ripps H (1998) Cloning and expression of two related connexins from the perch retina define a distinct subgroup of the connexin family. J Neurosci 18:7625-7637.

Ogata N, Ohishi Y (2002) Molecular diversity of structure and function of the voltage-gated $\mathrm{Na}^{+}$channels. Jpn J Pharmacol 88:365-377.

Peinado A, Yuste R, Katz LC (1993) Extensive dye coupling between rat neocortical neurons during the period of circuit formation. Neuron 10:103-114.

Pereda A, Faber D (1996) Activity-dependent short-term plasticity of intercellular coupling. J Neurosci 16:983-992.

Pereda A, Triller A, Korn H, Faber DS (1992) Dopamine enhances both electrotonic coupling and chemical excitatory postsynaptic potentials at mixed synapses. Proc Natl Acad Sci USA 89:12088-12092.

Pereda A, Nairn A, Wolzson L, Faber DS (1994) Postsynaptic modulation of synaptic efficacy at mixed synapses on the Mauthner cell. J Neurosci 14:3704-3712.

Pereda A, Bell T, Faber DS (1995) Retrograde synaptic communication via gap junctions coupling auditory afferents to the Mauthner cell. J Neurosci 15:5943-5955.

Pereda A, Bell T, Chang B, Czernik A, Nairn A, Soderling T, Faber DS (1998) $\mathrm{Ca}^{2+} /$ calmodulin-dependent kinase II mediates simultaneous enhancement of gap junctional conductance and glutamatergic transmission. Proc Natl Acad Sci USA 95:13272-13277.

Pereda A, O’Brien J, Nagy JI, Bukauskas F, Davidson KGV, Kamasawa N, Yasumura T, Rash JE (2003a) Connexin35 mediates electrical transmission at mixed synapses on Mauthner cells. J Neurosci 23:7489-7503.

Pereda A, O’Brien J, Nagy JI, Smith M, Bukauskas F, Davidson KGV, Kamasawa N, Yasumura T, Rash JE (2003b) Short-range functional interaction between Connexin 35 and neighboring chemical synapses. Cell Commun Adhesion 10:419-423.

Piccolino M, Neyton J, Gerschenfeld H (1982) Decrease of gap junction permeability induced by dopamine and cyclic adenosine $3^{\prime}: 5^{\prime}$ monophosphate in horizontal cells of turtle retina. J Neurosci 2:2477-2488

Ringham GL (1975) Localization and electrical characteristics of a giant synapse in the spinal cord of the lamprey. J Physiol (Lond) 251:395-407.

Schmitz D, Schuchmann S, Fisahn A, Draguhn A, Buhl EH, Petrasch-Parwez E, Dermietzel R, Heinemann U, Traub RD (2001) Axo-axonal coupling. A novel mechanism for ultrafast neuronal communication. Neuron 31:831-834.

Slesinger P, Bell CC (1985) Primary afferent fibers conduct impulses in both directions under physiological stimulus conditions. J Comp Physiol 157:15-22.

Smith M, Pereda A (2003) Chemical synaptic activity modulates nearby electrical synapses. Proc Natl Acad Sci USA 100:4849-4854.

Spira ME, Spray DC, Bennett MV (1976) Electrotonic coupling: effective sign reversal by inhibitory neurons. Science 194:1065-1067.

Staftsrom CE, Schwindt PC, Crill WE (1982) Negative slope conductance due to a persistent subthreshold sodium current in cat neocortical neurons in vitro. Brain Res 236:221-226.

Staftsrom CE, Schwindt PC, Chubb MC, Crill WE (1985) Properties of a persistent sodium conductance and calcium conductance of layer $\mathrm{V}$ neurons from cat sensorimotor cortex in vitro. J Neurophysiol 53:153-170.

Traub RD (1995) Model of synchronized population bursts in electrically coupled interneurons containing active dendritic conductances. J Comp Neurosci 2:283-289.

Trussell LO (1997) Cellular mechanisms for preservation of timing in central auditory pathways. Curr Opin Neurobiol 7:487-492.

Verselis VK, Ginter CS, Bargiello TA (1994) Opposite voltage gating polarities of two closely related connexins. Nature 368:348-351.

Watanabe S, Satoh H, Koizumi A, Takayanagi T, Kaneko A (2000) Tetrodotoxin-sensitive persistent current boosts the depolarization of retinal amacrine cells in goldfish. Neurosci Lett 278:97-100.

Yang XD, Korn H, Faber DS (1990) Long-term potentiation of electrotonic coupling at mixed synapses. Nature 348:542-545.

Zipser B (1979) Voltage-modulated membrane resistance in coupled leech neurons. J Neurophysiol 42:465-475. 